\title{
Adaptive Models for the Energy Efficiency of Building Envelopes
}

\author{
Martino Milardi
}

\author{
Department of Architecture and Territory, University Mediterranea of Reggio Calabria, Via Melissari, \\ 1 - 89124, Reggio Calabria, Italy
}

\begin{abstract}
The debate on energy efficiency in buildings has already established the strategic role of the envelope to achieve the control objectives of consumption and housing quality. The study shows, it ranks in the innovative experimentation scenario, following the directions of the regulations 2010/31/EU (EPBD 2) and its objective is the realization of a building envelope "adaptive", characterized by the ability to dynamically respond to stress from the environmental context with which it relates.

The experiment aimed at perfecting a model of intervention that can guide the design choices towards elements that make up the building envelope, characterized by a strong interactive-adaptive component. This is based on the combination of: layers of innovative envelope, systems using RES and SMART management requirements of the system, with a focus on intelligent control energy flows between external/internal and adaptive performance of the layers. The mode of "deferred layering" in relation to the orientation of the building and to climate periods, while for the control of wrap responses subjected to environmental stress, the research adopts BEMS \& BIM systems and other related criteria will be defined.

The experiment aims to satisfy the requirements to improve the energy performance of buildings by reducing the impacts (emissions), through the development of a technical system.

The results obtained from inspections in progress, show that the constituent layers that envelope react in a synergistic way and adapted to different climatic conditions, ensuring high-quality performance, in line with the energy efficiency targets established by regulatory standards.
\end{abstract}

Keywords: Building energy performance, SMART Building envelope, Energy efficiency, Integrated design, Adaptive components, Up-coming technologies.

\section{INTRODUCTION}

The debate on energy efficiency in buildings has already established the strategic role of the envelope to achieve the control objectives of consumption and housing quality. The study shows, it ranks in the innovative experimentation scenario, following the directions of the regulations 2010/31/EU (EPBD 2) 2012/27/UE and its objective is the realization of a building envelope "adaptive", characterized by the ability to dynamically respond to stress from the environmental context with which it relates.

This paper refers to an experience, in progress, of a research aimed at the implementation of elements of building envelope with a strong interactive component / adaptive based on renewable energy sources and remote management systems. This means the "technology system integration" and functional between the layers constituting the element in relation to the orientation of the building and the different seasonal climatic periods. These characteristics also means materialized through the adoption of remote management systems can define answers performance envelope because of the environmental stress.

*Address correspondence to this author at the Department of Architecture and Territory, University Mediterranea of Reggio Calabria, Via Melissari, 1 - 89124, Reggio Calabria, Italy; Tel: +3909651697112; Fax: +3909651697112;

E-mail: mmilardi@unirc.it
This is because the centre of gravity is in the building envelope, energy equipment and performance monitoring and management. Envelope is a critical element to reach the 2030 decarbonization goals (indeed according to US DOE 33 estimation) the building envelope impacts $57 \%$ of the building thermal loads [1].

The research is collocated in the validation phase methodological and technical development of the pattern simulation.

\section{Scope and Ambitions}

The experiment aimed at perfecting a model of intervention that can guide the design choices towards elements that make up the building envelope, characterized by a strong interactive-adaptive component. This is based on the combination of: layers of innovative envelope, systems using RES and SMART management requirements of the system, with a focus on intelligent control energy flows between external/internal and adaptive performance of the layers. The mode of "deferred layering" in relation to the orientation of the building and to climate periods, while for the control of envelope responses subjected to environmental stress, the research adopts BMS/BEMS \& BIM systems and other related criteria will be defined. The Ambitions of this study is to satisfy 


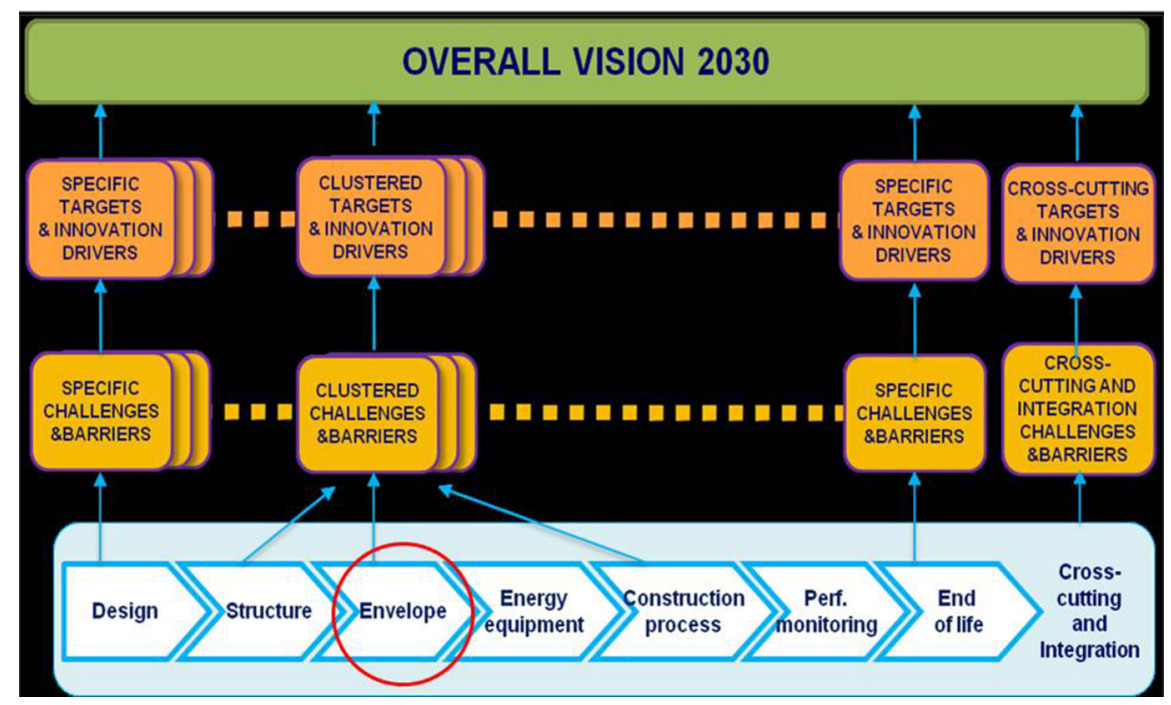

Picture 1: The role of the building envelope for the decarbonisation goals of the European Union by 2030.

the requirements to improve the energy performance of buildings by reducing the impacts (energy \& material flow, emissions, ecc.), through the development of a technical system capable of:

Designing high layer adaptivity for both materials characteristics of mechanical responses;

- $\quad$ Obtain the passive monitoring of heat flows by combining delayed sequence of layers of opaque components, translucent and transparent;

- $\quad$ Actively adjust the natural ventilation;

- Creation of surfaces that can integrate systems for the production of photovoltaic and thermal energy.

The results obtained from research in progress, show that the constituent layers that envelope react in a synergistic way and adapted to different climatic conditions, ensuring high-quality performance, in line with the energy efficiency targets established by regulatory standards.

\section{THE STARTING POINTS}

The contemporary scene that sets up the theme of energy efficiency in housing defines a complex scenario where the demand for low energy buildings become a common element between the different fields of study and application.

Between the leading principles and building pillars of R\&D there is the main line: adaptive, interactive and sustainable buildings, request by the European Union.
These "key principles" identified as starting point to create the desired breakthrough acceleration and implementation in the sustainable building sector.

Some priorities in different positions in the value chain have been identified as: Design; Integrated holistic - multi-target design; Tools to disclose existing knowledge and technologies; Structure - The building envelope as: Energy equipment and systems, Advanced heating/cooling and domestic hot water solutions, (including renewable energy sources); Thermal storage; Distributed/decentralised energy generation at district level; Construction Processes; ICT aided construction; Improving delivered energy performance; Automated construction tools; Performance monitoring and management, ICT interoperability, Smart Energy Management systems;

Table 1: Strategies and Criteria for the Building Envelope Project

\begin{tabular}{|c|c|}
\hline Main category & Subcategory \\
\hline 1. Tools for EE design and production & $\begin{array}{l}\text { - Design } \\
\text { - Production management } \\
\text { - Modelling } \\
\text { - Performance estimation }\end{array}$ \\
\hline 2. Intelligent control & $\begin{array}{l}\text { - Automation \& control } \\
\text { - Monitoring } \\
\text { - Quality of service } \\
\text { - Wireless sensor networks }\end{array}$ \\
\hline 3. User awareness \& decision support & $\begin{array}{l}\text { - Performance management } \\
\text { - Visualization of energy use } \\
\text { - Behavioural change }\end{array}$ \\
\hline 4. Energy management \& trading & $\begin{array}{l}\text { - Building energy management } \\
\text { - District energy management } \\
\text { - Smart grids and the built environment }\end{array}$ \\
\hline 5. Integration technologies & $\begin{array}{l}\text { - Process integration } \\
\text { - System integration } \\
\text { - Knowledge sharing } \\
\text { - Interoperability \& standards }\end{array}$ \\
\hline
\end{tabular}


Knowledge sharing; End of life; Decision-support on renovation or new buildings and associated solutions.

The guidance criteria that led to the definition of the patterns were based on:

- Active envelope, a package of technical solutions and associated control-command systems dedicated to the control and management of solar inputs or its thermal inertia;

- Adaptable \& Adaptive, The meaning of 'adaptable' is twofold: for a building/envelope/ component, it means that it is designed in such a way that, over time, it can be readily transformed to accommodate uses for which it was not originally conceived and facilitate the conversion of rooms or buildings to new usage, the adaptation to the users' evolution (people ageing), and the integration of new solutions (upcoming technologies). An adaptive envelope is also able to adapt to a dynamic and intricate environment by measuring and processing multisources information in order to respond to the building occupant's instructions and to evolving environmental conditions in an appropriate timing and extent [2].

- Integration, Whole-building integration is in principle similar to the process used in the automotive industry: ideally, every part would be designed and manufactured to work together to create high-performance buildings. The process begins with computer simulated design to analyze building components and systems, and then integrates them so that the overall building performance is optimized. A systems integration approach enables advanced technologies to function more efficiently while still meeting the challenging reliability and cost requirements for buildings [3].

- Envelope Targets, Energy efficient buildings will use envelopes that are durable, adaptable, usercentric and cost effective. Envelopes become more resistant to external (i.e. climate, fire, and natural hazards) and internal aggressions (moisture): they require less maintenance and allow for easier and better-quality maintenance work. Thermal bridges are addresses and the ageing of components is better understood which allows appraising their loss of performance over time.

Among the different Target defined by the state of the art research lies in particular:

1. Envelopes are adaptive and adaptable to a dynamic and complex environment.

The envelope functional characteristics enable the building envelope to adapt to a dynamic and complex environment during its lifetime ("Perception, Reasoning, Action"). Envelopes also facilitate the future renovation or conversion of the whole or part of the building fostering creativity and an active role of architects and engineers at some design stage.

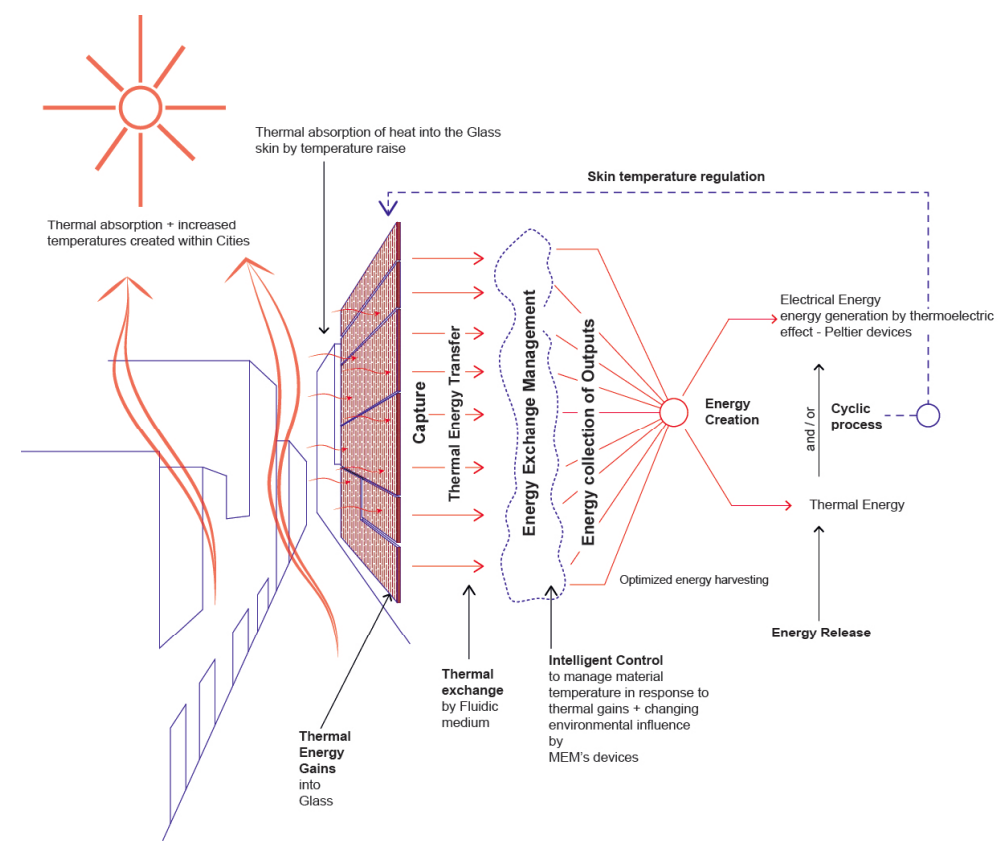

Picture 2: Pattern of intelligent skin. 
2. Envelopes are able to integrate generation and conversion of incoming solar radiation

With the following targeted areas:

- Development and manufacturing of envelope improving and optimising natural light and ventilation inside building;

- Development and manufacturing of energy storing converting materials (e.g., Phase Change Materials and switchable glazing (e.g. thermochromic, photochromic or electrochromic) combined with $\mathrm{PV}$ in glazing panes);

- Development of semi permeable insulation membranes and pigments with adaptable absorption reflection spectrum, Façade component with changing IR absorption and reflection on demand in combination with insulation and switchable U-values;

- $\quad$ Seamless system integration of ICT components used to optimise the real time performance of envelopes;

- Improved flexible and durable façade systems with movable sun barriers;

- $\quad$ Full scale demonstrations of adaptable envelope integration in building refurbishment projects, including smart insulation materials (e.g. aerogels, vacuum insulation panels or other innovative materials);

- Full scale demonstrations of adaptable envelope integration in district refurbishment project.

- $\quad$ Smart building envelopes capable of adapting their energy generation and storage to external condition;

- Integration of existing and innovative PV components (e.g. OPV, DSSC) into building envelopes;

- System integration of "thermally activated" material to reduce energy consumption.

Such synthetic background highlights how, in particular, the casing, invested by the universe of signals that qualify the external environment, reacts with specific reactivity, natural or dependent adjustments plant. The casing is then the physical element of mediation between external and internal environment and can transform, enhance, reduce, modular physical signals thermal, acoustic, light coming from the outside, making it a signal generator in which the environmental quality depends on the graduation and control [4].

From this interpretation are evident the design potential in the development of new systems of housing-oriented goals of environmental quality and sustainable development.

Build, in fact, it is increasingly necessary capacity to ensure high levels of comfort and at the same time helping to reduce greenhouse gas emissions means major energy savings. In this sense there is no doubt as the chassis as a system and, above all, the parameter of "differentiation" in relation to the environment / climate play an increasingly important role.

Against this background, and although they may have more options and technical materials are witnessing a strong homogeneity packet envelope, as well as their location in relation to the different orientations of the prospectuses. The result would be, therefore, lower the energy load of buildings on the one

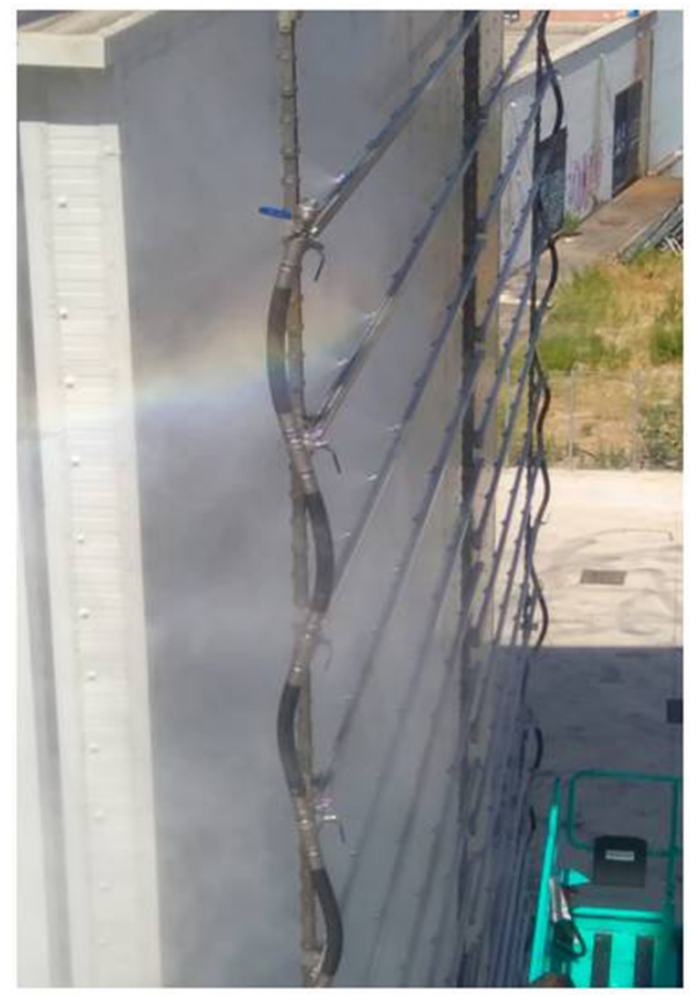

Picture 3: Watertightness laboratory test under static pressure for the research object envelope building (ASTM E 331). TCLab of Building Future Lab. Mediterranean University of Reggio Calabria - Italy. 
hand by consuming less, the other producing energy through the exploitation of energy capacity during the year [5].

Control strategies in the Italian case, especially the southern Italy may differ greatly from site to site as different can be the potential of the force of nature that is positive and negative. Applications in our country tend to largely transfer model solutions in Europe without any assessment of consistency with respect to our climatic conditions. Compared to the climate of the Northern Alpine countries, the Italian climate is characterized by warmer summers that compromise the efficiency of these solutions in the summer.

\section{PROBLEMATICS AND GOALS}

The foregoing try more critical nodes within the building made in Italy. This is due to the particular alternation climate that if one side is a fertile field from which to draw resources, on the other determines situations of discomfort housing which often increases the energy-consuming character of the buildings. The overall objective is to contribute to lowering the energy intensity of the Mediterranean cities and their simultaneous improvement of the overall environmental quality, to support the development of the know-how of local and global companies, to contribute to innovation in the construction industry.

Specifically, the trial is to develop a technical system can understand and compose in sequence deferred layers opaque, translucent and transparent for passive control of heat flows (from EPS insulation, PCM, TIM, aerogels or ceramic materials).

Similarly, these layers of the envelope systems respond to the stresses of the context variables, and of the different climatic periods, in a synergistic way, interactive and adaptive form, through remote management operations in order to ensure high quality performance, in line with the energy efficiency targets low impact.

In particular, we want to create patterns with specific characteristics of interchangeability of the layers in relation to the placement (be postponed in stratigraphic relationship to be postponed prospectuses), ability to plant integration whether in sheet or tube (producing thermal energy), ability to secure anyway the performance of the flow control capabilities through its thermophysical material, then offered in the form of performance passive, because of the performance of energy-saving, environmentally interactive ability to type / adaptive through remote management.

To meet these requirements has developed a testing pattern of intervention, called: P1E, Energy Saving Photovoltaic Ceramic Frame, which brings with it the following objectives:

- Increase the indoor hygrometric conditions (aesthetic and architectural)

- Mitigation of the heat loss of the building envelope

- Home Energy Savings and reduction of Co2 Emissions

- Sound insulation of the building envelope

- Use of local materials, dry mounted on site

- $\quad$ Production of Solar Power

The objective of the specific Pattern is the realization of a ventilated wall made of ceramic material, which also can produce photovoltaic energy through the insertion of pigments $\mathrm{PV}$ to insert in ceramic coating.

We consider the ventilated walls as the natural evolution of the housing system of southern Italy, aimed at saving energy. They were created to protect buildings from temperature and atmospheric agents, thus ensuring a normal residential try to eliminate the problems caused by other types of external insulation. This system is very effective. In fact, it brings many innovations and architectural solutions of technological performance, such as: A high degree of industrialization of the components, A technique for fast and easy installation, which allows easy maintenance of the elements without difficulty, The use of architectural elements both new construction and existing buildings.

The ventilated wall is a wall of the facade where the outer shell can be made from slabs of "different nature" (ceramic) assembled in a "dry process".

The presence of the interspace obtained is generated a flow of air upward, driven by the thermal gradient, due to the temperature difference between the external environment and the interior of the interspace.

At the base of the interspace is placed a grid so as to allow a passage of air and, at the same time, to 
avoid the introduction of small animals. In the upper part there is placed a flashing to let out the air and to prevent the entry of water.

In addition, a factor that greatly influences the performance of the ventilated wall is the cavity air flow.

The pattern consists of renewable materials and aimed at energy savings with a system of intelligent energy management through sophisticated mechanisms of control and coordination for the management of demand efficient and reliable (DSM) [6].

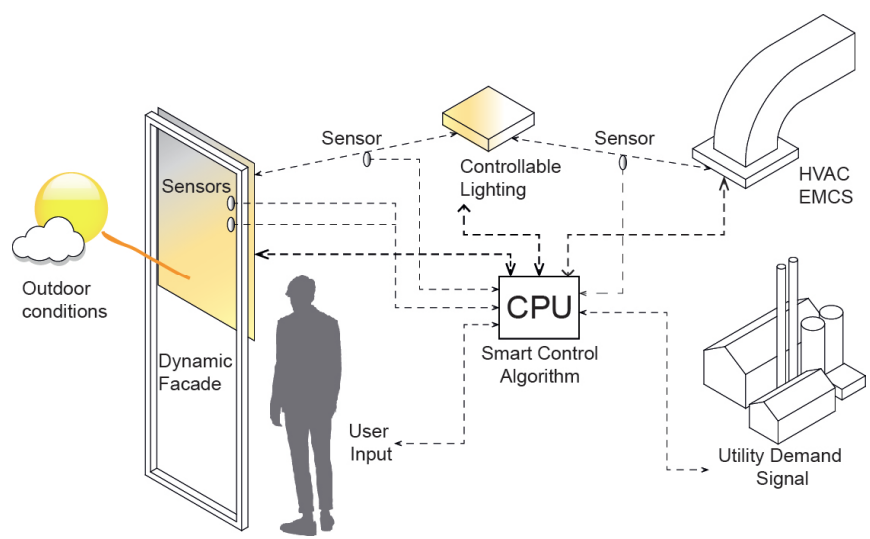

Picture 4: Example of an intelligent management scheme for reducing the energy consumption of the building envelope.

The system will coordinate:

- Local power generation (by photovoltaic elements)

- Local power consumption

- Heating/cooling/air conditioning/aeration

- $\quad$ Electric consumer load

- Connected devices infrastructure (i.e. IT networking, wired and wireless)

- Local recharging of batteries of any kind

- Stationary batteries

- Electrical vehicles of any kind

- SmartPhones, torches

Assistance helping the user to understand the impact of weather, daylight and distribution network demand (through price signals)

- $\quad$ Scheduling of recharging events
- $\quad$ Scheduling of usage of larger power consumers (dish washer, washing machine)

- $\quad$ Scheduling of power feedback to the grid

Assistance can be provided for controlling climate and lighting in the home

- $\quad$ Automatic control of blinds, lamps

- Transmissibility of windows, doors, walls, roofs

Can be achieved by

- Using smart materials

- Installing sensors (temperature, light, humidity, movement, ...)

Analysing power consumption to find usage and consumption patterns (energy disaggregation)

- Analysing human activity or inactivity (presence, entertainment, health, ...)

\section{THE METODOLOGY}

The fundamental concept is that our homes are poorly constructed and consume too much energy. So it is necessary to intervene on improving existing building in order to increase the efficiency from the point of view of energy about the internal, external and acoustic insulation.

This solar wall ceramic ventilated produce energy in an integrated manner, on the one hand and on the other hand reduces the percentage of $\mathrm{CO} 2$, and through lower $\mathrm{CO} 2$ emissions, in order to reduce harmful emissions of air conditioning and pollution considered by urban mobility.

The photovoltaic wall will be involving different disciplines, such as nanotechnology that are relevant to the photovoltaic paint, the land for the cultivation of hemp, the architecture for the design of the wall, the electronics for the distribution of electricity, home automation to calibrate the exact flow of heat and energy, and to identify the thermal properties, the medicine as it reduces respiratory diseases due to the suppression of indoor pollution (causing infections by molds and lichens).

The positioning of the project is $40 \%$ on the development of the idea of application and in the meantime $60 \%$ of the laboratory to the marketplace. 
The idea will be developed independently from the laboratory to the objectives and expected results of the verification in the various fields of research.

The activities related to the verification of the results before and after the application of the ventilated wall application will be realized thanks to the specific software that is in phase of development.

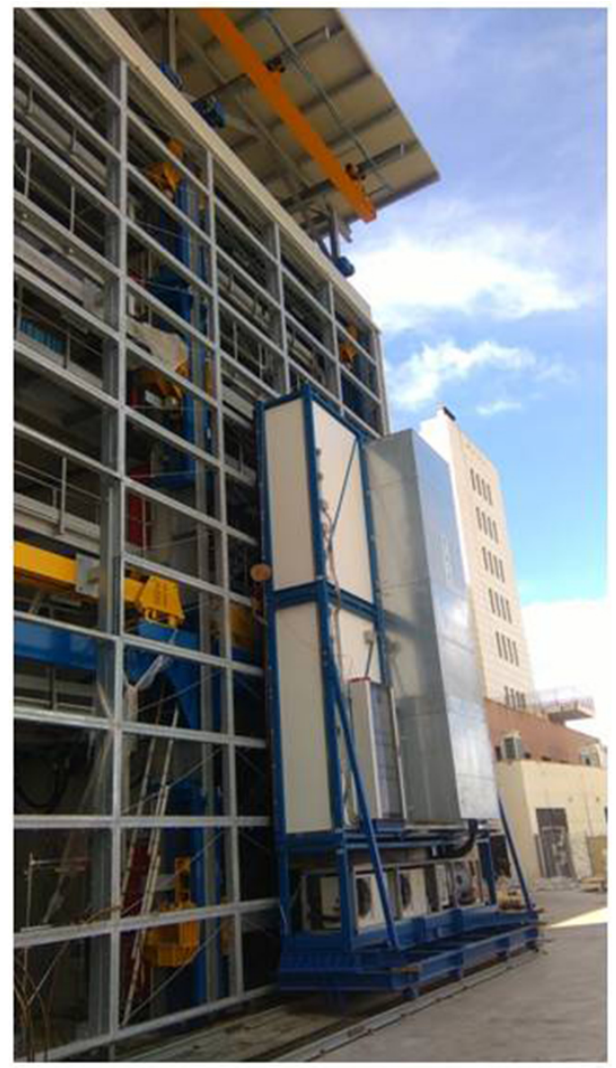

Picture 5: Thermal Chamber for the experimentation of the thermal and luminous flux of the building envelope object of research. TCLab of Building Future Lab. Mediterranean University of Reggio Calabria - Italy.

The diagnostics of the existing building as a starting point, that sample surveys of the entire national territory through data processing tools to inspect walls.

The methodology will be inductive. The program will apply the following steps:

- diagnosis on the building with existing data acquisition through the thermal camera on a sample of cases distributed at different latitudes of the European continent and Africa;

- design of ventilated wall, in the light of the acquired data that will be modified according to the different latitudes (sun, outside temperature, humidity, etc ...);
- small-scale prototyping and verification of results;

- realization of a prototype of the actual size of the wall fanned and verification of results;

- laboratory tests on the performance of the wall itself thermo ventilated;

- $\quad$ on-site examinations to be mounted on buildings in appropriate locations.

In the definition of the processes of planning and execution of the test, you have to use different skills in it, the partners will provide equipment and men, in order to contribute to the realization of the prototype of the wall and on a large scale.

\section{Approaches and Strategies of Reference}

"...Design strategies for building envelopes are a relatively recent opportunity for building designers. In the past, locally available materials and successful past precedents guided a highly traditional building industry where certain types of performance problems, were considered acceptable. .... Today, a multitude of performance requirements must be satisfied amid a marketplace of innovative materials, components, and systems the designer is responsible to fully integrate, and the constructor must properly deliver. Picking a suitable generic building enclosure typology is an important first step..." [7].

In relation to up said, today, intervention strategies for the realization of adaptive envelopes include various relationships that have a direct impact on performance, such us:

- Inaccuracy and inconsistency of processing and materials, in combination with the variable atmospheric conditions, resulting in buildings that only approximately meet their design intent.

- $\quad$ The approaches are based on the physical and climatic phenomena and their direct impact on the building envelope system.

- The envelope as container, must be able to adequately control the moisture migration, the transfer of heat, air leakage and the solar radiation.

Considering how up said, it is then defined some strategies for the formulation of new adaptive systems 
Table 2: Climatic Classification of Italian Municipalities (D.P.R. n. 412/1993)

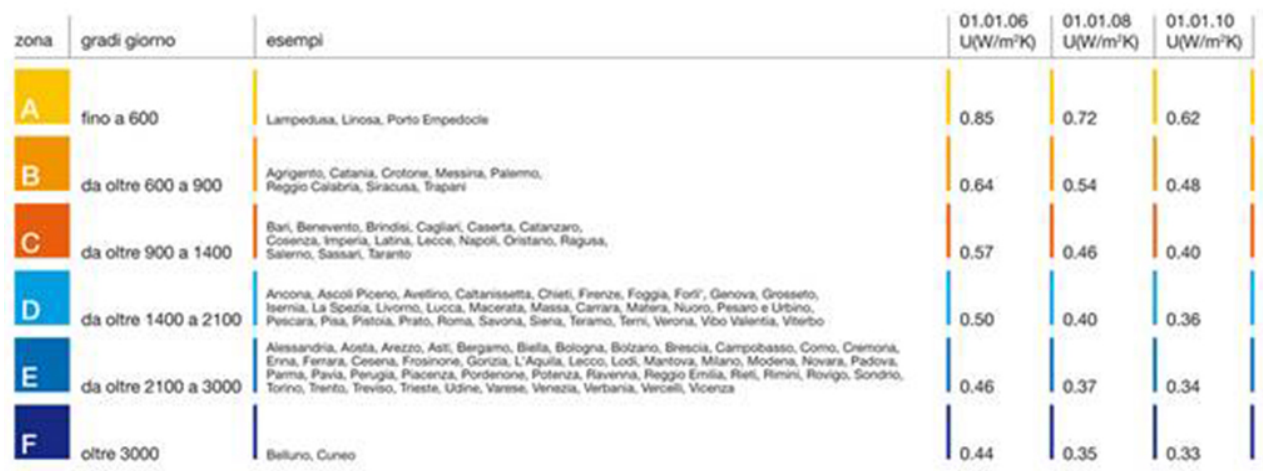

that could achieve smart performance of the building envelope, in particular:

Separator Vs Moderator: these relationships guide the designers to control measures and compensation.

Strategy to "climatic zones": the design of an effective building envelope must adequately consider the following factors: Climate zone (location of the building); Annual Exhibition of rainfall and the prevailing stresses; Use destination; Energy Profile

Other strategies: The following approaches has identified additional strategies in order to build the repertoire on which experiment with different housing solutions that are being defined, from the adaptive passive according to the adaptive-integrated technology-based smart.

In particular, the scenario has identified the following strategies:

- Building Energy Profile. From an energy efficiency and thermal comfort perspective, buildings are often classified according to the primary drivers for space conditioning loads.

- Design \& Materials. In order to appreciate the approaches involved in building enclosure system design strategies, it is important to understand several key relationships that impact performance.

- Building Envelope Typologies: Dynamic Buffer Zone; Perfect Barrier; Mediators; Graduated; Storage and Drying; Pressure Moderated Drainscreens; Pressure-Equalized Rain Screens.

\section{THE ACTIVITIES}

1. Definition through the research program of the project design and execution criterias of the ventilated wall;
2. Diagnosis of the walls through nonlinear signal processing, signal processing applications for ultrasonic systems, infrared and bioacustic signal processing.

3. Implementation of a prototype, first on a small scale, then on a real scale for the definition of all the parts that contribute to the formation and definition of the wall;

4. Implementation of an intelligent energy management system at home that coordinates

- Local power generation (by photovoltaic elements)

- Local power consumption

\section{Expected Results}

Today ventilated walls have reached a high degree of technological innovation and with this research are expected energy savings based on the use of renewable energy. The use of solar energy to meet our energy needs is certainly the easiest and most immediate way to reduce emissions of carbon dioxide in the atmosphere. On average, the amount of carbon dioxide (greenhouse gas) produced by a Photovoltaic system is approximately $0.35 \mathrm{~kg}$ per $\mathrm{KWh}$. Considering the traditional sources of energy, the Photovoltaic system allows a saving of about $780 \mathrm{~kg} /$ year of CO2 per kilowatt installed [8].

\section{INNOVATIVE ASPECTS}

The innovation consists in the study of materials and the development of technologies to produce a "photovoltaic surface" directly in the current tile production process, so as to preserve the technical characteristics, and at the same time to make available new surfaces capable of exploiting sources energy 


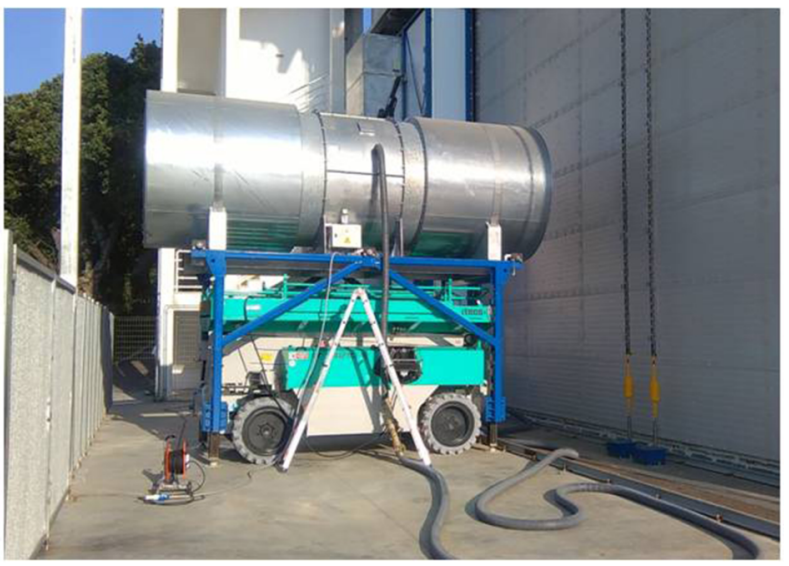

Picture 6: Wind load simulator for testing the permeability of the building envelope object of research $\sim 200 \mathrm{Km} / \mathrm{h}$. AAMA 501.1-05 "Standard Test Method For Water and Air Penetration Of Windows, Curtain Walls And Doors Using Dynamic Pressure". TCLab of Building Future Lab. Mediterranean University of Reggio Calabria - Italy.

sources. This approach goes in the direction of integrating photovoltaic elements in building elements according to an increasingly popular trend. The importance of identifying the exploitation of solar energy the goal of functionalization has important ecological implications, and derives from the need to respond to a pressing global energy demand. Ceramic tiles are large and growing application in the construction of ventilated walls. They can be defined as the opaque walls of the facade, where the outer shell is made up of elements of various shapes, put in place by suspension devices and attachment of mechanical and hidden side which is separated from the front to the back wall. The ventilated façade system allows to obtain interesting and practical advantages in terms of thermal comfort, humidity and noise of the buildings, security, management and maintenance of the facades. Focusing attention on ceramic tiles for coating facades of buildings with the aim to functionalize the exposed surface of the tiles, by adding value to the passive protection offered by the ventilated walls. The objective of the research is the study and implementation of a carry, applied on ceramic tile, replacing the glaze usually used with a surface capable of transforming the radiation of sunlight into electrical energy using the photovoltaic effect and identifying materials with appropriate properties for the realization of a conductive metallic coating for the formation of contacts on the front and back of the photovoltaic cell itself. The objectives of the research will also focus on the enlargement of the photovoltaic action, which allow you to get tile size to be used as a coating of the building envelope, such as that of ventilated walls.
With this pattern products combine innovation with traditional systems, looking for a combination of engineering which raises the quality of housing and increases the level of comfort.

\section{CONCLUSIONS}

The study is placed in the scenario of European policies based on Directives 2002/91/ EU, 2010/31/EU and $2012 / 27$ UE where are indicated the targets for reducing GHG emissions and confirmed the concept of near-zero energy building. To meet those needs has gradually revealed the need to develop innovative enclosures high energy performance that require technical systems increasingly turned to the logic of complex integration. However, there is no doubt as the actual offering of the envelopes performance may vary depending on the environment conditions for which this is a very important aspect for research practice.

With the aim to respond to these requests research she has focused efforts starting from the assumption that current envelopes guarantee thresholds consistent performance and calibrated on the average values provided by the regulations, resulting envelope that have the same performance even in different contextual conditions. So, that research, though still in progress, pursues the idea that the envelopes manufactured according to this method may provide reliable levels of efficiency because, not only are calibrated on the contextual conditions that determine the choice of technical structures, but react to same context according adaptive dynamics, based smart, that increase energy quality. Clearly, the research cannot be considered exhaustive due to the complexity of the energy topic on building sector. There are several variables and new innovation fields to investigate, in fact, the future steps that will complete this research are already oriented towards the application opportunities of this method trusting that has the objective of developing a smart skin system integrated to an intelligent system able to play a key role in the technological evolution of high performing architectural envelopes, and then that intelligent building means proposing new solutions of active envelope, able to reduce the environmental impact of the systems related to the construction field.

Based on the above said, using this type of pattern, in addition to energy savings, there are also some advantages for the environment, such as the reduction of $\mathrm{CO} 2$ emissions; saving fossil fuel, use of renewable energy sources... 
To these advantages are also associated with superior physical characteristics and material properties of fact, the ceramic has a good heat resistance; a very high melting point; ease of processing in the natural state (which allows the production of different forms); excellent durability; good fire resistance, in fact, the ceramic does not burn and does not emit any substance in contact with fire; the duration of the colors in direct contact with sunlight; is waterproof and resistant to moisture, frost, wear, chemicals, stains, absorption,...

All these features are the result of the combination of the natural qualities of the material and those arising from the particular processes that ceramics suffers from the man, according to the intended use of the material.

\section{REFERENCES}

PPP Energy-efficient Buildings Towards the creation of a high-tech building industry. Turning energy efficiency into sustainable business Research \& Innovation Roadmap 201420

[2] Gregory D.P. Adaptive Building Envelopes (No. BSRIA-TN3/86). Bracknell 1986.

[3] Compagno A. Intelligent Glass Façades. Berlin: Eds. Birkhauser Publishers 2002.

[4] Brian A. Intelligent Buildings: Applications of IT and Building Automation to High Technology Construction Projects. London: Eds. Kogan Page 1998.

[5] Daniels K. Low Tech - Light Tech - High Tech. Building in the Information age. Berlin: Eds. Birkhauser Publishers 2001.
[6] Andrew H. Intelligence Quotient: Smart Tips for Smart Buildings, DEGW, Architecture Today, AT46. London: Eds. EMAP Publishing Ltd Company 1994.

[7] Swinton M.C. and Kesik, T. Performance Guidlines for Basement Systems and Materials: Final Report, Institute for Research in Construction, National Research Council Canada, Ottawa, October 2015

[8] IPCC Special Report on Renewable Energy Sources and Climate Change Mitigation. Prepared by Working Group III of the Intergovernmental Panel on Climate Change [O. Edenhofer, R. Pichs-Madruga, Y. Sokona, K. Seyboth, P. Matschoss, S. Kadner, T. Zwickel, P. Eickemeier, G. Hansen, S. Schlömer, C. von Stechow (eds)]. Cambridge University Press, Cambridge, United Kingdom and New York, NY, USA, 1075 pp. (Chapter 7 \& 9). IPCC, 2011.

[9] ARUP Deutschland $\mathrm{GmbH}$, [Internet] Cities Alive. Green Building Envelope. Berlin: Konigsdruck Printmedien, 2016 (consulted on XXX). Available by: https://www.arup.com/ perspectives/themes/cities/cities-alive

[10] Danner D., Hassler F.H., Krause J.R. Die klima-active Fassade; Leinfeld-Echterdingen: Eds. Alexander Koch $\mathrm{GmbH} ; 1999$.

[11] ICBEST: 2014: Proceedings of the International Conference on Building Envelope Systems \& Technologies in Aachen Germany: (09-12 Jun 2014), 2014.

[12] Lstiburek J. [Internet] The Perfect Wall. Building Science Insights. Published on 11 June 2008. Available by: https://buildingscience.com/documents/insights/bsi-001theperfect-wall.

[13] Milardi M. The energy intensity as a new parameter for the value performance of the envelope of building stock. Paper presented at the 3rd International Conference on Central Europe towards Sustainable Building (CESB13), Czech Technical University, Prague, 2013.

[14] Wigginton M. and Harris J. Intelligent Skins, Oxford: Eds. Architectural Press 2002. 